\title{
A Novel Photochromic System of 4,5-Dialkenylthiophenes Constructed by the Samarium Diiodide Promoted Coupling Reactions of Thiophene-2-carboxylate with Aryl Ketones
}

2002

Vol. 4, No. 7

1099-1102

\author{
Jiun-Jie Shie, Shyh-Ming Yang, Chao-Tsen Chen, and Jim-Min Fang ${ }^{\star}$ \\ Department of Chemistry, National Taiwan University, Taipei 106, \\ Taiwan, Republic of China \\ jmfang@ccms.ntu.edu.tw
}

Received December 20, 2001

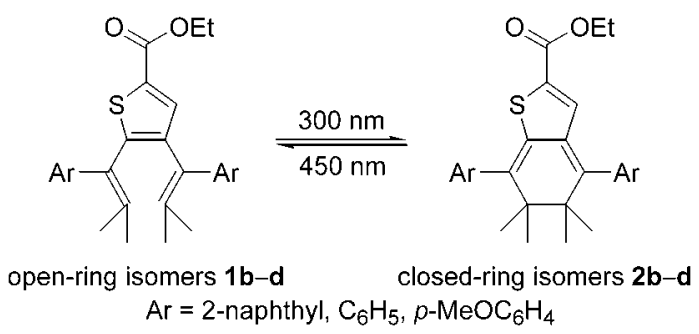

The $\mathrm{Sml}_{2}$-promoted coupling reaction of ethyl thiophene-2-carboxylate with aryl ketones (2 equiv), followed by acid-catalyzed dehydration and oxidative aromatization, gave dialkenylthiophenes $1 \mathrm{~b}-\mathrm{d}$, which underwent electrocyclizations upon irradiation with $300-\mathrm{nm}$ light in $\mathrm{CH}_{3} \mathrm{CN}$ solution to give the corresponding closed-ring species with absorption $\lambda_{\max } \approx 425 \mathrm{~nm}$. The interconversion between dialkenylthiophenes and their corresponding closed-ring species constitutes a novel photochromic system bearing an ester group for potential uses in linkage and wavelength tuning.

Photochromism is a light-induced reversible isomerization between two forms having different absorption spectra. The photochromic system based on the interconversion of 1,3,5hexatriene to cyclohexadiene has been extensively investigated, ${ }^{1}$ partly as a result of their potential applications to optical memories and switches. The photocyclization of stilbene to dihydrophenanthrene is a well-known photochromic system. ${ }^{2}$ According to the Woodward-Hoffmann rule, ${ }^{3}$ the double bond of stilbene should have $(Z)$-configuration

(1) For reviews, see: (a) Laarhoven, W. H. In Photochromism: Molecules and Systems; Dürr, H., Bouas-Laurent, H., Eds.; Elsevier: Amsterdam, 1990; Chapter 7, pp 270-313. (b) Irie, M.; Uchida, K. Bull. Chem. Soc. Jpn. 1998, 71, 985. (c) Organic Photochromic and Thermochromic Compounds; Crano, J. C., Guglielmetti, R. J., Eds.; Plenum Press: New York, 1999. (d) Irie, M. Chem. Rev. 2000, 100, 1685. to conform a concerted conrotatory cyclization in the photochemical conditions. Dihydrophenanthrene can return rapidly to stilbene in the dark; however, it can also undergo oxidative aromatization in the presence of oxygen. ${ }^{2} \mathrm{By}$ replacing the phenyl rings with thiophene rings, 1,2-di(3thienyl)ethene undergoes a photocyclization reaction to give the closed-ring species with an improved stability. ${ }^{4}$ This

(2) Muszkat, K. A.; Fischer, E. J. Chem. Soc. C 1967, 662. (e) Repinec, S. T.; Sension, R. J.; Szarka, A. Z.; Hochstrasser, R. M. J. Phys. Chem. 1991, 95, 10380.

(3) (a) Dewar, M. J. S. Angew. Chem., Int. Ed. Engl. 1971, 10, 761. (b) Zimmerman, H. E. Acc. Chem. Res. 1971, 4, 272. (c) Nakamura, S.; Irie, M. J. Org. Chem. 1988, 53, 6136.

(4) Kellogg, R. M.; Groen, M. B.; Wynberg, H. J. Org. Chem. 1967, 32,3093 . 
result is attributed to the low aromatic stabilization energy difference between the open- and closed-ring isomers of thiophene by comparison with that of benzene. ${ }^{1 b, 3 c}$ Irie and co-workers further demonstrate that the light-induced cyclization of 1,2-bis(2,4-dimethylthien-4-yl)perfluorocyclopentene gives a stable colored species. ${ }^{1 \mathrm{~b}}$ The cyclopentene ring incorporates the requisite double bond of the $(Z)$ configuration, and the methyl groups at the 2- and $2^{\prime}$ positions prevent the closed-ring species from oxidative aromatization.

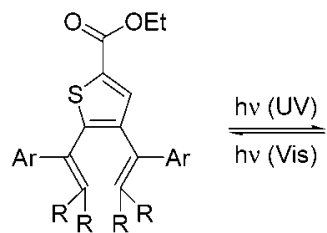

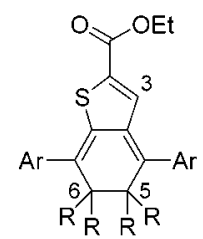

closed-ring isomer

$$
\begin{array}{lll}
\text { 1a } & \mathrm{Ar}=2 \text {-naphthyl, } \mathrm{R}=\mathrm{H} & \mathbf{2 a} \\
\text { 1b } & \mathrm{Ar}=2 \text {-naphthyl, } \mathrm{R}=\mathrm{Me} & \mathbf{2 b} \\
\text { 1c } & \mathrm{Ar}=\mathrm{C}_{6} \mathrm{H}_{5}, \mathrm{R}=\mathrm{Me} & \mathbf{2 c} \\
\text { 1d } & \mathrm{Ar}=p-\mathrm{MeOC}_{6} \mathrm{H}_{4}, \mathrm{R}=\mathrm{Me} & \mathbf{2 d}
\end{array}
$$

We report herein a novel photochromic system (eq 1) based on the interconversion between 4,5-dialkenylthiophenes $\mathbf{1 a}-\mathbf{d}$ and their closed-ring isomers $\mathbf{2} \mathbf{a}-\mathbf{d}$. Dialkenylthiophene $\mathbf{1 a}-\mathbf{d}$ were readily prepared by a threestep sequence (Scheme 1): (i) coupling of ethyl thiophene-

\section{Scheme $1^{a}$}
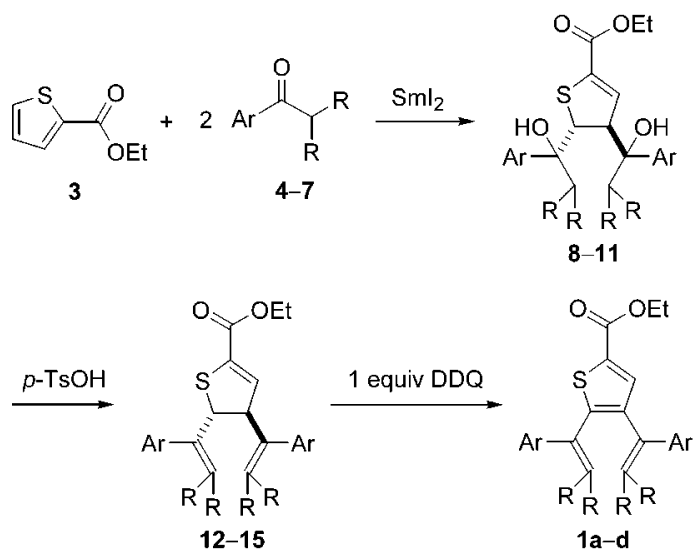

For compounds 1a, 4, 8 and 12: $\mathrm{Ar}=2$-naphthyl, $\mathrm{R}=\mathrm{H}$ For compounds 1b, 5, 9 and 13: $A r=2$-naphthyl, $R=M e$ For compounds 1c, 6, 10 and 14: $\mathrm{Ar}=\mathrm{C}_{6} \mathrm{H}_{5}, \mathrm{R}=\mathrm{Me}$ For compounds 1d, 7, 11 and 15: $\mathrm{Ar}=p-\mathrm{MeOC}_{6} \mathrm{H}_{4}, \mathrm{R}=\mathrm{Me}$

${ }^{a}$ Reagents and conditions: (i) $\mathrm{SmI}_{2}$, THF, HMPA, $25{ }^{\circ} \mathrm{C}, 12-$ 24 h. 8, 50\% yield; 9, 43\%; 10, 32\%; 11, 37\%. (ii) Cat. $p$-TsOH, $\mathrm{PhH}$, reflux, $4-12$ h. 12, 95\% yield; $\mathbf{1 3}, 87 \% ; \mathbf{1 4}, 67 \% ; \mathbf{1 5}, 73 \%$. (iii) For 1a, DDQ, $\mathrm{PhH}, 60^{\circ} \mathrm{C}, 12 \mathrm{~h} ; 83 \%$ yield. For $\mathbf{1 b}-\mathbf{d}$, DDQ, $\mathrm{PhCH}_{3}$, reflux, 24 h; 1b, 69\% yield; 1c, $80 \%$; 1d, $84 \%$.

2-carboxylate (3) with aryl ketones 4-7 (2 equiv) by the promotion of $\mathrm{SmI}_{2}$, giving diols 8-11, ${ }^{5}$ (ii) acid-catalyzed dehydration, giving dienes 12-15, and (iii) oxidation by DDQ (1 equiv), giving dialkenylthiophenes $\mathbf{1 a}-\mathbf{d}$. The central double bonds of $\mathbf{1 a}-\mathbf{d}$ were confined in the thiophene ring to adopt a $(Z)$-configuration required by the concerted electrocyclizations.

The UV-vis spectrum of dialkenylthiophene $1 \mathbf{a}^{6}$ exhibited $\lambda_{\max }$ at $242 \mathrm{~nm}(\epsilon=38800)$ and $289 \mathrm{~nm}(\epsilon=13800)$. Upon irradiation of 1a (colorless solution) with 300-nm light, an orange color immediately appeared, indicating the existence of new species. The reaction course of $\mathbf{1 a}$ in $\mathrm{CDCl}_{3}$ (ca. 0.1 M) was recorded by the ${ }^{1} \mathrm{H}$ NMR spectra. ${ }^{7}$ After irradiation for 10 min, closed-ring species $\mathbf{2 a}$ (ca. 30\%) was produced as inferred from a new set of proton signals, in which a singlet at $\delta 2.99$ was ascribed to the methylene protons of tetrahydrobenzothiophene moiety. The ratio of $\mathbf{2} \mathbf{a}$ increased as the irradiation progressed to $60 \mathrm{~min}$. However, several other compounds including benzothiophene $\mathbf{1 6}^{8}$ and 6,7dihydrobenzothiophene $17^{9}$ were also produced at the expense of $\mathbf{2 a}$ (Scheme 2).

\section{Scheme 2}
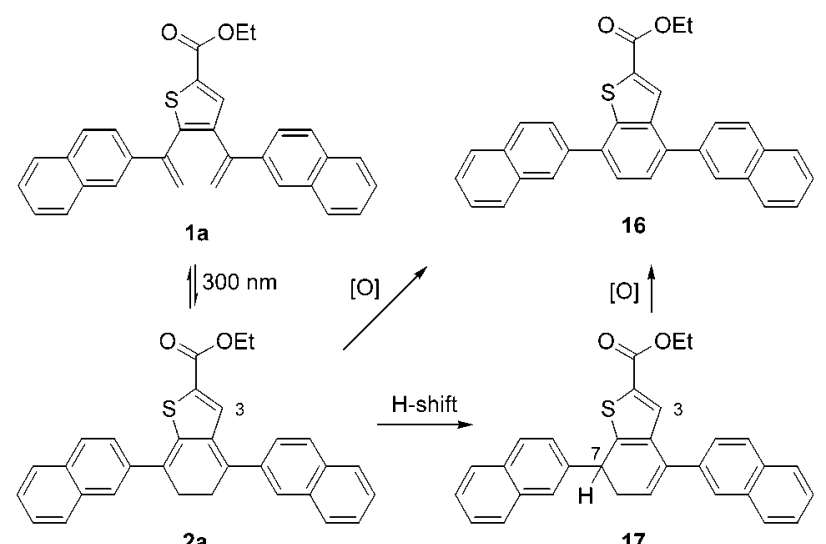

$2 a$

17
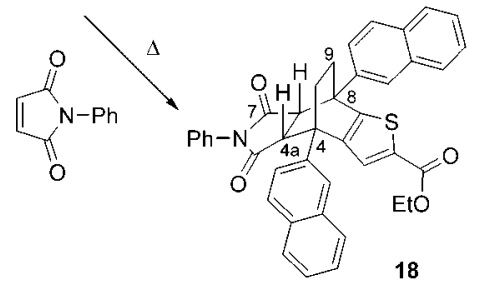

Compound 16 was likely obtained by an oxidative aromatization of $\mathbf{2 a}$ similar to that proposed in the conversion

(5) (a) Yang, S.-M.; Fang, J.-M. Tetrahedron Lett. 1997, 38, 1589. (b) Yang, S.-M.; Nandy, S. K.; Selvakumar, A. R.; Fang, J.-M. Org. Lett. 2000, 2,3719 .

(6) Compounds $\mathbf{1 a}-\mathbf{d}$ and $\mathbf{8}-\mathbf{1 8}$ were fully characterized by spectral methods (IR, UV, MS, HR-MS, ${ }^{1} \mathrm{H}$ and ${ }^{13} \mathrm{C}$ NMR). The details are reported in Supporting Information, whereas some pertinent physical and spectral properties are herein listed. Compound 1a: solid, mp $109-111{ }^{\circ} \mathrm{C}$; UV $\left(\mathrm{CHCl}_{3}\right) \lambda_{\max }(\epsilon) 242 \mathrm{~nm}$ (38800), $289 \mathrm{~nm}$ (13800); FL $\left(\mathrm{CHCl}_{3}, c=2 \times\right.$ $\left.10^{-4} \mathrm{M}\right) \lambda_{\mathrm{em}} 415 \mathrm{~nm}$ on excitation at $364 \mathrm{~nm} ;{ }^{1} \mathrm{H} \mathrm{NMR}\left(\mathrm{CDCl}_{3}, 300 \mathrm{MHz}\right)$ $\delta 7.77(1 \mathrm{H}, \mathrm{s}), 7.73-7.70(2 \mathrm{H}, \mathrm{m}), 7.58-7.54(4 \mathrm{H}, \mathrm{m}), 7.44-7.36(6 \mathrm{H}$, m), $7.16(1 \mathrm{H}, \mathrm{dd}, J=8.5,1.5 \mathrm{~Hz}), 7.10(1 \mathrm{H}, \mathrm{dd}, J=8.5,1.5 \mathrm{~Hz}), 5.57$ $(1 \mathrm{H}, \mathrm{s}), 5.50(1 \mathrm{H}, \mathrm{s}), 5.41(1 \mathrm{H}, \mathrm{s}), 5.35(1 \mathrm{H}, \mathrm{s}), 4.38(2 \mathrm{H}, \mathrm{q}, J=7.3$ $\mathrm{Hz}), 1.39(3 \mathrm{H}, \mathrm{t}, J=7.3 \mathrm{~Hz})$. Compound 1b: UV $\left(\mathrm{CHCl}_{3}\right) \lambda_{\max }(\epsilon) 290$ $\mathrm{nm}$ (35400). Compound 1c: UV $\left(\mathrm{CH}_{3} \mathrm{CN}\right) \lambda_{\max }(\epsilon) 249 \mathrm{~nm}(34400), 300$ $\mathrm{nm}$ (16800). Compound 1d: UV $\left(\mathrm{CH}_{3} \mathrm{CN}\right) \lambda_{\max }(\epsilon) 251 \mathrm{~nm}(34900), 300$ nm (13700).

(7) The photochemical reactions were conducted in a Rayonet photochemical reactor using 300 or 450-nm lamps. The corresponding NMR and UV-vis time course spectra are included in Supporting Information. 
of dihydrophenanthrene to phenanthrene. When the photochemical reaction of $\mathbf{1 a}$ was conducted in deoxygenated $\mathrm{CD}_{3^{-}}$ $\mathrm{CN}$ solution, the formation of $\mathbf{1 6}$ was inhibited. Compound 17 might be derived from 2a by an H-shift. Attempts to isolate 2a failed, presumably because of its instability. Attempts to trap the transient closed-ring species $\mathbf{2 a}$, as an $o$-thiophenequinodimethane, by $\mathrm{N}$-phenylmaleimide in the photochemical reaction of dialkenylthiophene 1a (300-nm, $\mathrm{CH}_{3} \mathrm{CN}, 25^{\circ} \mathrm{C}, 48 \mathrm{~h}$ ) also failed, even though the existence of $2 \mathbf{a}$ could be inferred from a newly occurring NMR signal at $\delta 2.99$ (s). However, $2 \mathbf{a}$ was alternatively generated by the thermal electrocyclization of $\mathbf{1 a}$ in refluxing toluene and successfully trapped by $\mathrm{N}$-phenylmaleimide to give a $\mathrm{C}+$ 2] cycloaddition product $\mathbf{1 8} \cdot{ }^{10}$ Although the trapping experiment under thermal conditions should not be strictly correlated to the photochemical reaction of 1a, this result lent a clue to intermediate $\mathbf{2} \mathbf{a}$ in support of the newly NMR signal at $\delta 2.99$ found under photochemical conditions.

The drawbacks of oxidative aromatization and $\mathrm{H}$-shift would be avoided in the photochemical cyclization of trienes $\mathbf{1 b}-\mathbf{d}$ as they have C-5 and C-6 positions substituted by methyl groups. When a colorless acetonitrile solution $\left(1.1 \times 10^{-5} \mathrm{M}\right)$ of $\mathbf{1 b}$ was irradiated with $300-\mathrm{nm}$ light at room temperature, the 290-nm absorption of $\mathbf{1 b}$ decreased along with the growth of a new 429-nm absorption attributed to the formation of the yellow closed-ring species $\mathbf{2 b}$ (Figure 1). The corresponding ${ }^{1} \mathrm{H}$ NMR spectra ${ }^{7}$ also showed a newly

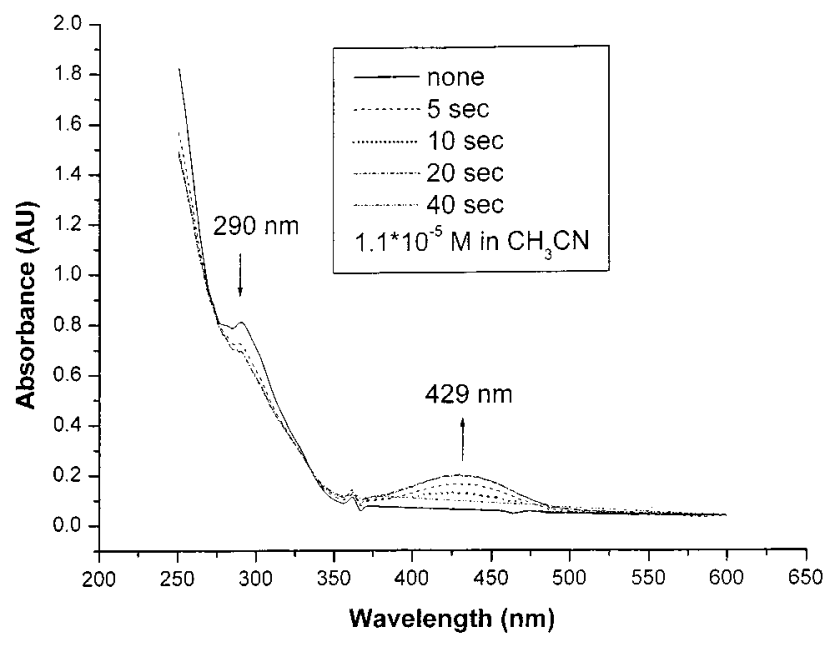

Figure 1. The UV-vis spectral change of compound $\mathbf{1 b}$ on irradiation with 300 -nm light at $25{ }^{\circ} \mathrm{C}$ in $\mathrm{CH}_{3} \mathrm{CN}$ solution.

occurring singlet $(\delta$ 6.64) ascribed to the H-3 of $\mathbf{2} \mathbf{b}$. According to the NMR study, the maximal content of the

(8) For comparison, an authentic sample of $\mathbf{1 6}$ was also prepared by treatment of triene 1a with DDQ in refluxing toluene. Compound 16 exhibited a characteristic $\mathrm{H}-3$ at $\delta 8.27$ (s).

(9) Compound $\mathbf{1 7}$ was isolated by chromatography of the reaction mixture at the interval of 90-min irradiation of 1a. The structure of $\mathbf{1 7}$ was tentatively assigned according to the ${ }^{1} \mathrm{H}$ NMR, HR-MS, and NOE analyses. There is no enhancement of H-3 at $\delta 7.68$ (s) on irradiation of H-7 at $\delta 4.53$ (t, $J=$ $9 \mathrm{~Hz})$. closed-ring species $\mathbf{2 b}$ was estimated to be $15 \%$ in the reaction mixture under the photochemical conditions (30 min at $-20{ }^{\circ} \mathrm{C}$ in $\mathrm{CD}_{3} \mathrm{CN}$ solution).

The photochemical properties of $\mathbf{1 c}(\mathrm{Ar}=\mathrm{Ph})$ and $\mathbf{1 d}$ $\left(\mathrm{Ar}=p-\mathrm{MeOC}_{6} \mathrm{H}_{4}\right)$ were similar to that of $\mathbf{1 b}(\mathrm{Ar}=$ 2-naphthyl), even though they had different aryl groups. Irradiation of $\mathbf{1 c}$ and $\mathbf{1 d}$ with $300-\mathrm{nm}$ light in $\mathrm{CH}_{3} \mathrm{CN}$ solution afforded the closed-ring species $\mathbf{2 c}$ and $\mathbf{2 d}$, which showed absorption maxima at 422 and $425 \mathrm{~nm}$, respectively. ${ }^{7}$ On the basis of these results, the moiety of $o$-thiophenequinodimethine carboxylate in $\mathbf{2 b}-\mathbf{d}$ was likely the main contributing chromophore. The absorption change in $\mathbf{2 b}-\mathbf{d}$ was trivial, as their aryl substituents might not be coplanar to the chromophore.

We also demonstrate that the closed-ring species $\mathbf{2} \mathbf{b}-\mathbf{d}$ are photochemically reversible. ${ }^{11}$ When a mixture of $\mathbf{1 b} / \mathbf{2} \mathbf{b}$ and $\mathbf{1 d} / \mathbf{2 d}$ was irradiated with 450-nm light, respectively, $\mathbf{2 b}$ and $\mathbf{2 d}$ disappeared and returned rapidly (within $1 \mathrm{~min}$ ) to the open-ring species (1) and $\mathbf{1 d}$ ). The interconversion between $\mathbf{1 c}$ and $\mathbf{2 c}$ was realized by alternate irradiation with UV (300-nm) and visible (419-nm) lights at 10-s intervals. In a preliminary experiment, the absorption intensity at 424 $\mathrm{nm}$ showed a significant change after irradiation of $\mathbf{1 c} / \mathbf{2 c}$ for several cycles (see Supporting Information).

The ring-closure and ring-opening reactions as shown in eq 1 should be both photochemically and thermally allowed. The closed-ring species were unstable on standing at room temperature, and they returned to the open-ring species in the dark. For example, a mixture of $\mathbf{1 b} / \mathbf{2 b}$ (ca. 85:15) obtained by irradiation of $\mathbf{1 b}$ with $300-\mathrm{nm}$ light for $40 \mathrm{~s}$ in $\mathrm{CH}_{3} \mathrm{CN}$ was removed from the light source and allowed to stand at room temperature in the dark. According to the absorption intensity changes at 290 and $429 \mathrm{~nm}, \mathbf{2 b}$ returned to $\mathbf{1 b}$ to a considerable degree $(\sim 20 \%)$ in the first minute and $\mathbf{2 b}$ completely disappeared in $40 \mathrm{~min}^{7} \mathrm{~A}^{\mathrm{A}}$ mixture of $1 \mathbf{c} / 2 \mathbf{c}$ (ca. 82:18) also behaved similarly to give exclusively 1c after standing at room temperature for $24 \mathrm{~h}$ in the dark. This interconversion was monitored by ${ }^{1} \mathrm{H}$ NMR spectra, in which the characteristic $\mathrm{H}-3$ signal of $\mathbf{1 c}$ (singlet at $\delta$ 7.52) increased as that of $\mathbf{2 c}$ (singlet at $\delta$ 6.22) disappeared. ${ }^{7}$

In summary, the interconversion between dialkenylthiophenes $\mathbf{1 b}-\mathbf{d}$ and their corresponding closed-ring species constitutes a novel photochromic system. The preparation of $\mathbf{1 b}-\mathbf{d}$ is simple by using readily available starting materials via a three-step sequence (Scheme 1), though the yield is not yet optimized. The ester group in trienes $\mathbf{1 b}-\mathbf{d}$ may serve as a linker to polymeric supports or undergo functional group transformation to tune the photochemical properties. The closed-ring species $\mathbf{2} \mathbf{b}-\mathbf{d}$ are unstable and return to $\mathbf{1 b}-\mathbf{d}$ in the dark even at room temperature. The photochemical and thermal stability of these substrates must be improved in order to reach a practical application of this novel dialkenylthiophene/dihydrobenzothiophene system.

The elegant diarylethene photochromic system developed

(10) Compound $\mathbf{1 8}$ had the endo-configuration as its NOESY spectrum showed a correlation of $\mathrm{H}-4 \mathrm{a} / \mathrm{H}-7 \mathrm{a}(\delta 4.34-4.33, \mathrm{~m})$ with the ethylenebridge protons $(\delta 2.15-2.11, \mathrm{~m})$.

(11) Miyasaka, H.; Murakami, M.; Itaya, A.; Guillaumont, D.; Nakamura, S.; Irie, M. J. Am. Chem. Soc. 2001, 123, 753. 
by Irie and co-workers ${ }^{1 \mathrm{~b}, \mathrm{~d}}$ has demonstrated high quantum yield, thermal stability, and fatigue resistance. This system incorporates a central ring of perfluorocyclopentene with substitution of two aromatic rings. When the open isomer changes to the closed isomer upon irradiation, the two aromatic rings must change simultaneously to form another conjugated chromophore. In contrast, our current photochromic system utilizes a thiophenyl ring as the central moiety. The synthesis of the photo-/thermochromic substrates of dialkenylthiophenes is relatively easy by using the commercially available starting materials of thiophene-2-carboxylate and aryl ketones. Furthermore these two aryl groups are not incorporated into the contributing $o$-thiophenequinodimethane chromophore of the closed-ring species. This unique structure bearing two independent chromophores thus provides a good opportunity to build the photochromic system having a fluorescent sensing property. For example, one can replace the naphthyl ring in $\mathbf{1 b}$ by an appropriate coumarin as the acceptor chromophore for the light emitted from the closed-ring species, which is generated by UVlight irradiation. Modification of the ketone moieties in our current system would not be difficult. We are currently engaged in this endeavor to demonstrate such energy-transfer mechanism in a photochromic system.

Acknowledgment. We thank the National Science Council for financial support and Professor Pi-Tai Chou (National Taiwan University) for helpful discussion.

Supporting Information Available: Detailed experimental procedures, NMR and UV-vis spectra. This material is available free of charge via the Internet at http://pubs.acs.org.

OL0172830 